\title{
Integrating the RFID identification system for Charolaise breeding bulls with 3D imaging for virtual archive creation
}

\author{
Maria Grazia Cappai ${ }^{\text {Corresp.. }}{ }^{1}$, Filippo Gambella ${ }^{2}$, Davide Piccirilli ${ }^{2}$, Nicola Graziano Rubiu ${ }^{3}$, Corrado Dimauro \\ 4, Antonio Luigi Pazzona ${ }^{2}$, Walter Pinna ${ }^{1}$ \\ ${ }^{1}$ Research Unit for Animal Nutrition, Department of Veterinary Medicine, University of Sassari, Sassari, Italy, Italy \\ 2 Research Unit for Agriculture Engineering of the Department of Agriculture, University of Sassari, Sassari, Italy \\ 3 NurEID Foundation, Nuragus, Italy, Italy \\ 4 Research Unit for Animal Breeding Sciences of the Department of Agriculture, University of Sassari, Sassari, Italy, Italy \\ Corresponding Author: Maria Grazia Cappai \\ Email address: mgcappai@uniss.it
}

The individual electronic identification (EID) of cattle based on RFID technology ( $134.2 \mathrm{kHz}$ ISO standard 11784) will definitely enter into force in European countries as an official means of animal identification from July 2019. Integrating EID with 3D digital images of the animal would lead to the creation of a virtual archive of breeding animals for the evaluation and promotion of morphology associated with economic traits, strategic in beef cattle production. The genetically-encoded morphology of bulls and cows together with the expression in the phenotype were the main drivers of omic technologies of beef cattle production. The evaluation of bulls raised for reproduction is mainly based on the conformation and heritability of traits, which culminates in muscle mass and optimized carcass traits in the offspring destined to be slaughtered. A bottom-up approach by way of SWOT analysis of the current morphological and functional evaluation process for bulls revealed a technological gap. The innovation of the process through the use of smart technologies was tested in the field. The conventional 2D scoring system based on visual inspection by breed experts was carried out on a 3D model of the live animal, which was found to be a faithful reproduction of live animal morphology, thanks to the non significant variance $(p>0.05)$ of means of the somatic measures determined on the virtual 3D model and on the real bull. The four main groups composing the scoring system of bull morphology can easily be carried out on the 3D model. These are as follows: 1) Muscular condition; 2) Skeletal development; 3) Functional traits; 4) Breed traits. The 3D-Bull model derived from the Structure from Motion ( $\mathrm{SfM}$ ) algorithm displays a high tech profile for the evaluation of animal morphology in an up-graded system. 
1 Integrating the RFID identification system for Charolaise breeding bulls with 3D imaging

2 for virtual archive creation

3 Maria Grazia Cappai ${ }^{1}$, Filippo Gambella ${ }^{2}$, Davide Piccirilli ${ }^{2}$, Nicola Graziano Rubiu ${ }^{3}$, Corrado

4 Dimauro $^{4}$, Antonio Luigi Pazzona ${ }^{2}$, Walter Pinna ${ }^{1}$

$5{ }^{1}$ Research Unit for Animal Nutrition, Department of Veterinary Medicine, University of Sassari,

6 via Vienna no. 2 - 07100 - Sassari, Italy

$7 \quad{ }^{2}$ Research Unit for Agricultural Engineering of the Department of Agriculture, University of

8 Sassari, viale Italia, 39 - 07100 Sassari, Italy.

$9{ }^{3}$ NurEID Foundation, Piazza del Comune snc, 08030 - Nuragus, Italy.

$10{ }^{4}$ Research Unit for Animal Breeding Sciences, Department of Agriculture, University of Sassari, 11 viale Italia, 39 - 07100 Sassari, Italy.

12 Corresponding author: mgcappai@uniss.it 


\section{ABSTRACT}

14 The individual electronic identification (EID) of cattle based on RFID technology $(134.2 \mathrm{kHz}$

15 ISO standard 11784) will definitely enter into force in European countries as an official means of

16 animal identification from July 2019. Integrating EID with 3D digital images of the animal

17 would lead to the creation of a virtual archive of breeding animals for the evaluation and

18 promotion of morphology associated with economic traits, strategic in beef cattle production.

19 The genetically-encoded morphology of bulls and cows together with the expression in the

20 phenotype were the main drivers of omic technologies of beef cattle production. The evaluation

21 of bulls raised for reproduction is mainly based on the conformation and heritability of traits,

22 which culminates in muscle mass and optimized carcass traits in the offspring destined to be

23 slaughtered. A bottom-up approach by way of SWOT analysis of the current morphological and

24 functional evaluation process for bulls revealed a technological gap. The innovation of the

25 process through the use of smart technologies was tested in the field. The conventional 2D

26 scoring system based on visual inspection by breed experts was carried out on a 3D model of the

27 live animal, which was found to be a faithful reproduction of live animal morphology, thanks to

28 the non significant variance $(\mathrm{p}>0.05)$ of means of the somatic measures determined on the

29 virtual 3D model and on the real bull. The four main groups composing the scoring system of

30 bull morphology can easily be carried out on the 3D model. These are as follows: 1) Muscular

31 condition; 2) Skeletal development; 3) Functional traits; 4) Breed traits. The 3D-Bull model

32 derived from the Structure from Motion (SfM) algorithm displays a high tech profile for the

33 evaluation of animal morphology in an up-graded system. 


\section{Introduction}

38 The current identification system for cattle in European Union countries will be modified starting

39 from $18^{\text {th }}$ July 2019 , the date on which EU Reg 911/2004 will be implemented. The individual

40 electronic identification (EID) of cattle based on radio frequency technology (RFID, $134.2 \mathrm{kHz}$ )

41 will become an official means of cattle identification, in addition to the double plastic ear tag

42 identification system (EU Reg 1760/2000). The automatic RFID-based identification of cattle

43 will be part of the innovation process of animal recording, encompassing a digitized and real

44 time automatically generated database, within the so-called Precision Livestock Farming (PLF).

45 In view of the potential offered by RFID technology, several perspectives may lead to advanced

46 production systems, of particular importance both for regulation compliance and the profitable

47 management of herds. In this scenario, production goals differ depending on whether dairy or

48 beef cattle are considered. Modern beef cattle production relies on decades of animal selection,

49 oriented to the improvement of breeding system efficiency, basically to reduce costs and increase

50 profits. Bovine breeds display morphological differences relating to production goals, if dairy or

51 beef cattle are considered. In particular, beef cattle breeds are selected to improve carcass worth

52 and the evaluation of body morphology of the live animal encompasses the interplay between

53 genetic selection, breeding practices and expression of desirable traits. In 2007, Nkrumah and

54 coworkers correlated genetic and phenotypic behaviour based on economically relevant traits

55 (ERT) in Angus and Charolaise breeds, including feed intake, feed conversion ratio, fertility and temperament as those with a direct impact on the management and sustainability of the beef

57 cattle farming system. The genetic value of animals is meant to spread to the whole herd since

58 the productivity and sustainability of the farm does not rely on the single individual. In view of

59 this aspect, the very accurate selection of breeding bulls and cows by the farmer is carried out to 
60 optimise production performance, which represents the main economic driver of beef cattle

61 herds. In light of recent research conducted worldwide and of the ever more sophisticated

62 genomic techniques, the latest achievements by genetic investigations on beef cattle (Burrow and

63 Dillon 1997; Voisinet et al., 1997; Gibb et al., 1998; Sowell et al. 1998; Burrow and Corbet,

64 2000; Schwartzkopf-Genswein et al., 2003; Robbinson and Oddy 2004; Nkrumah et al., 2007;

65 Moore et al., 2017; Su et al., 2017; Leal et al., 2018; de Souza Fonseca et al., 2018; Soulat e al.,

662018 ; ) outline the need to obtain very specialized morphological lines of animals, with typical

67 body measurements and breed conformation.

68 Several breeds of genetically selected beef cattle are acknowledged worldwide to be of elevated

69 performance, and the Charolaise breed is one of these. This cattle breed originated in Bourgogne

70 (France) and is characterized by the high quality of meat and acclimation characteristics (Briggs

71 and Briggs, 1980). Nowadays, Charolaise beef cattle can be considered cosmopolite farm

72 animals for meat production, along with some other breeds acknowledged worldwide to be

73 selected for highly specialized traits. In Italy, the association of Charolaise and Limousine

74 farmers (A.N.A.C.L.I.) was founded in 1987 with the creation of breed Registry Records at

75 national level. The presence of the Charolaise breed in Italy is considerable and the Sardinia

76 region contributes considerably to Italian beef meat production in terms of the number of heads

77 raised (14,463 Charolaise heads, source A.N.A.C.L.I., 2016).

78 Breeding bulls are selected by the farmer according to the type of herd and management. The

79 most common type belongs to the "souche bouchér" line for the production of offspring with

80 high live weight at birth and rapid skeletal and muscular development. Heifers or steers are

81 normally slaughtered at an age of 16-18 months and weight to slaughter of about $650 \mathrm{~kg}$. 
82 The economic value of the breeding bull is strongly influenced by the morphological evaluation

83 carried out in regional and national fairs for livestock, in which animals are scored by breed

84 experts. As recently evaluated in a bio-economic model by Leal and co-workers (2017), the

85 dressing percentage, associated with carcass weight at slaughter and relative yield, in Angus

86 cattle is that with the largest economic value within herd productions. This concept may be

87 applied to all beef cattle breeds.

88 It is important to underline that while advanced omic technologies have been used for decades in

89 livestock sciences with particular regard to cattle, the evaluation of morphology through the

90 scoring system of animals still conserves old-fashioned methods. The score attributed to the

91 morphology of the breeding bull has an impact on the economic value of the animal and its

92 progeny and increases the visibility of the farmer, who selects and raises animals for

93 competitions. At present, different morphological sections are scored through an evaluation grid

94 displaying a 2D schematic illustration of the generic bovine (Figure 1). The score sheet reported

95 in Figure 1 displays the official scoring system adopted by the A.N.A.C.L.I.(2009). Breed

96 experts judge animals in annual competitions on the basis of a semi-quantitative evaluation,

97 based on the harmonic proportions of animal development, the morphology of anatomical

98 districts and functional traits with direct impact on carcass composition. To a great extent, the

99 overall evaluation is based on the experience of the breed evaluator and is carried out by

100 classifying the animal according to: 1) Muscular condition; 2) Skeletal development; 3)

101 Functional traits; 4) Breed specific traits. At present, this system appears to be technologically

102 outdated if compared with the advanced technologies underlying the achievements of modern

103 breed traits. In view of this gap, smart technologies largely adopted in the beef cattle sector (such

104 as RFID, omic sciences, artificial insemination) have great potential for system improvement, as 
105 these may provide valid tools to implement the process for the evaluation of the breeding bull in

106 a modern system. Against this backdrop, the goal of a competitive strategy relies on profitable

107 and sustainable productions with regard to external competition (environmental or extrinsic

108 competition) to strengthen the competitive internal advantages.

109 Precision livestock farming (PLF) has entered livestock farms relatively recently. The efficiency

110 of management was to be improved by way of smart technologies in terms of several aspects of

111 the everyday breeding practices of food producing animals (Banhazi et al, 2012;Berckmans,

112 2014; Fournel et al., 2017), particularly of cattle. It was hypothesized that the contactless, real

113 time and digitalized recording of animal data could be the starting point to both internal and

114 external competitive evaluation of the Charolaise breeding bull. In particular, 3D imaging is a

115 technology that is widely deployed in several sectors. In livestock, the deployment of the

116 technology based on 3D digital imaging is in its infancy and the few papers on this topic testify

117 to the cutting edge research exploring this new frontier of PLF (Konsgro, 2014; D'eath et al.,

118 2018). This paper describes an innovative and technological method that was explored to assess

119 the potential of the integration of RFID for animal identification with 3D images of the real bull

120 for the evaluation of the Charolaise breeding bull.

121 This research was undertaken with the aim of: a) carrying out a SWOT analysis to identify the

122 Strengths, Weaknesses, Opportunities and Threats of traditional vs. innovative processes of

123 morphology evaluation; b) testing the opportunity offered by the 3D digital model of the real

124 animal in comparison to the 2D grid of the scoring system based on biometric measures in the 125 perspective of a digital archive creation for e-commerce.

\section{Material and Methods}




\section{Animal care and identification}

128 The animals involved in this study were cared for according to European Union legislation on

129 animal protection and welfare (EU Reg 2010/63/EU). The trial involved two Charolaise bulls

130 from the same farm which were 3 and 4 years old, multi-champions of breed and category both

131 at regional and national level. The two bulls enrolled in the trial possess high morphological and

132 genetic value and serve as breeders for all the cows raised on the same farm (total heads raised

133 excluding calves $=46$ ). In addition, their semen is also sold for artificial insemination (AI) on

134 other farms. Bulls on one farm can also serve several other farms, thus the impact on offspring is

135 multiplied for the desirable traits that farmers intend to introduce to their own herd. Raising too

136 many breeding bulls in the same herd would not be economically viable because AI can provide

137 high profits with few, but highly selected animals. The choice to involve these two breeding

138 bulls was therefore driven by conventional farm management practices on one hand and by their

139 morphological value on the other.

140 Each bull was electronically identified with an endoruminal bolus (75 g. 70x21mm RUMITAG

141 bolus ${ }^{\circledR}$ ) holding a passive HDX transponder (Radio Frequency134.2 kHz, 32.5×3.8 mm, ISO

142 11784-11785 Tiris $32 \mathrm{~mm}$ ), on voluntary basis. In compliance with current European mandatory

143 rules (EU Reg 1760/2000) for the individual identification of cattle, the bulls were also identified

144 with double plastic eartags.

\section{In vivo body measuring of the animals}

146 Both bulls (body weight between 1.27 and 1.3 tons) were individually handled in two distinct

147 moments and temporarily placed in a paddock with a flat concrete floor to allow the recording of

148 body measurements. Wither's height, trunk length and distance at thighs were taken with the 
149 Lydtin stick, on repeated measures until reaching the same value for three replicates. In this

150 regard, it is necessary to highlight that, while stressful condition were kept to a minimum and the

151 animals were familiar with the facilities and personnel, any sudden movement of the bull may

152 require several repetitions to measure one single parameter until a repeatable and acceptable

153 value could be safely achieved. All measurements were recorded and used to calculate

154 sensitivity and accuracy of in vivo vs. 3D model measurements.

\section{In field image capturing}

156 The acquisition of 2D digital pictures of the animal was carried out in a geo-referenced system

157 (Figure 2), where the bull stood in the centre of a circle ( $\mathrm{r}=6$ meters) purposely drawn on the

158 floor, in an area outside the barn, in natural daylight but in the shade of a shelter. The operator

159 captured images with a digital camera integrated in a mobile phone (8 Mpx, focus length 4.15

$160 \mathrm{~mm}$, exposure 1/1721) and moved along the circumference where reference points of known

161 dimensions were located. The choice to use an integrated camera in a mobile phone was made to

162 test whether a device that is easily available could be suitable for this purpose.

163 The number of pictures taken from the different angles was determined on replicates until

164 reaching the least frame capturing to obtain the best 3D textured model. The overlap extent of 165 sequential images taken along the circumference was no less than $70 \%$.

\section{Post acquisition processing}

167 The sets of images were elaborated with Agisoft Photoscan (Agisoft LLC C), Russia) software, 168 capable of performing photogrammetric processing of digital images and generating 3D spatial 169 data, with the algorithm based on Structure from Motion (SFM). Through different consecutive

170 steps starting from the chunk (the original digital image), the relative set of masks is created with 
171 the purpose of eliminating objects (masking the unnecessary objects of the picture) from the

172 background (Figure 3). The pictures are then aligned and a dense point cloud is generated

173 (Figure 4). Through the mesh of dense point clouds, the software finalizes the procedure through

174 texturing and builds up the so called "Doll" model, from which the 3D model can be exported

175 into different digital formats.

176 S.W.O.T. analysis of the process "as is" vs. "to be"

177 The bottom-up analysis of Strengths, Weaknesses, Opportunities and Threats was based on the

178 potential of the introduction of the 3D image technology compared with the current scoring 179 system for the beef bull.

180

- Definition of objectives

181

182

- Identification of users' needs

183

- Strategies to enhance value

184

SWOT analysis is based on intrinsic and extrinsic factors of the process that were analyzed as reported in Table 1.

In this context, the opportunity offered by electronic identification was explored in the perspective of the creation of a virtual database where 3D-images of bulls could be uploaded with the individual electronic identification code and the farm of origin. The implementation of the system with the introduction of such a new technological tool within the process would

191 contribute to identifying the objectives to satisfy the concept expressed by Guatri (1991),

192 according to whom the final goal of business relies on the capability of continuous auto-

193 regeneration over time, with the sustainable creation of economic value. 
194 In the light of the evaluation of the system "as is" (based on the current 2D evaluation score) and

195 "to be" (after the development of the 3D model for digital archiving and digital data sharing)

196 SWOT analysis was conducted to explore the introduction of 3D innovations to instrumental

197 management for the evaluation of the breeding bull. This evaluation therefore focused on the

198 specific extrinsic and intrinsic factors of the evaluation process to test whether the reduction of

199 the technological gap on the farm (bottom) offers opportunities for and/or poses threats to the

200 creation of economic value for farmers and, potentially, for stakeholders (scale-up).

\section{Calculations, data analysis and statistics}

202 A series of measurements for wither's height, body length and rear trimness was carried out in

203 vivo on each bull and on the respective 3D virtual model, until reaching the same value for three

204 replicates.

205 The positive predictive value (PPV), sensitivity (or true positive rate, TPR), specificity (or true

206 negative rate, TNR) and accuracy (ACC) of the biometric measurements determined on the 3D

207 model in comparison with those retrieved from the real animal were calculated using the

208 following formulas:

$$
P P V=\frac{T P}{(T P+F P)} \times 100
$$

$$
T P R=\frac{T P}{(F P+T N)} \times 100
$$

$$
T N R=\frac{T N}{(F P+T N)} \times 100
$$

$$
A c c=\frac{(T P+T N)}{(T P+T N+F P+F N)} \times 100
$$


213 where TP is the number of virtual measurements matching with real measurements, FP is the

214 number of different virtual measurements matching with real measurements, TN is the number of

215 different virtual measurements differing from the real measurements, FN is the number of

216 virtual measurements differing from real measurements.

217 The analysis of variance between means of the two series of measurements collected in vivo and

218 on the 3D virtual model was carried out by ANOVA with SAS 9.2 (SAS Inst. Inc. Cary, NC).

219 Results were considered statistically significant when $\mathrm{p}<0.05$. 


\section{Results}

221 The least frame capturing required 81 images in this trial, with an at least $70 \%$ overlap between

222 subsequent pictures on a $360^{\circ}$ total capturing per bull. The operator moved around the animal in

223 the geo-referenced system which allowed body proportions to be established. The process of

224 image capturing took between 20' and 22' per bull. Somatic measurements collected in vivo and

225 on the 3D-bull (Figure 5) did not differ in a significant way. When comparing the two systems

226 for taking somatic measurements the fact that no statistical significance between in vivo and

227 virtual values was detected appeared highly encouraging for the adoption of the system in the

228 field. Table 2 summarizes the results on 3D bull performance.

229 In Table 3, results from the SWOT analysis are reported. On the basis of the series of

230 measurements carried out both in vivo and on the $3 \mathrm{D}$ bull, the positive predictive value and the

231 accuracy of the system turned out to range from $89 \%$ to $100 \%$ for the three sets of body

232 measurements for wither's height, body length and rear trimness.

\section{Discussion}

234 The opportunity offered by 3D digital imaging to carry out body measurements on a 3D-bull

235 model improves the current system of morphological scoring considerably by objectifying

236 evaluations. Indeed, the 2D grid with a schematic illustration of the generic bovine has to be

237 filled in manually and does not allow any automation. On the other hand, the 3D bull is a faithful

238 reproduction of the live animal, and is hence highly suitable for the morphological evaluation

239 and appraisal of the genetic potential as a breeding bull through the phenotype.

240 Among the advantages offered by the 3D bull model, the collection of body measurements can

241 be carried out in a safe way, much more comfortably for both the breed evaluator and the bull. In 
242 fact, fairs and the presence of other bulls during the scoring process may represent a stressful

243 condition for the animal, which may react to the environmental stimuli in unpredictable ways.

244 While expert personnel and animal friendly facilities are provided during fairs, safe conditions

245 for operators and animal protection may be improved by the evaluation of the virtual model.

246 Additionally, 3D digital images of bulls saved in purposely created virtual archives may ease

247 access and the sharing of data among stakeholders. Such digital archives can greatly improve the

248 visibility of the genetic (through the individual electronic code for genealogy) and phenotypic

249 (morphological) value of the bull and potentially broaden the horizons of e-commerce if made

250 available to a network of stakeholders. This opportunity opens up a series of considerations

251 connected with different aspects of beef cattle management. When artificial insemination (AI) is

252 used, the opportunity offered by the digital evaluation of bull morphology would allow the

253 creation of a virtual archive for the e-commerce of semen from bulls with a high profile for

254 functional traits.

255 In the SWOT analysis of the evaluation process of Charolaise bull morphology, we identified

256 internal weaknesses in the costs of animal transport and animal welfare issues, both during

257 transportation and exposition in dedicated fairs. In the "as is" process, the farmer must subscribe

258 bulls to dedicated fairs both on regional and national levels, for which economic resources must

259 be set aside to cover travel and subscription costs. In the "to be" process, the farmer will be able

260 to subscribe animals to online virtual fairs, where animal morphology can be accessed by other

261 remote subscribers and stakeholders thanks to the electronic code associated with the 3D model

262 of the live bull. In this way, internal weaknesses can be minimized. The possibility of having a

263 virtual archive where digital images of animals can be reached by stakeholders means that the

264 animals do not have to be moved from the farm, hence offering substantial savings on travel 
265 costs. Reducing stress for the animals due to handling and their being loaded onto means of

266 transport to reach unfamiliar settings is in agreement with other efficient solutions proposed by

267 PLF (Banhazi et al., 2012; Berckmans, 2014) to optimise breeding and management practices on

268 site. However, as the system is somewhat advanced, some stakeholders may be unready for the

269 technology and this may lead to a delay in the standardization of the 3D-model based system.

270 Electronic identification through the RFID technology represents both a sound and reliable

271 method for animal identification and a very promising system for the implementation of a virtual

272 archive of recorded animals through the electronic digital number of the transponder, as observed

273 in other filiéres (Cappai et al., 2013, 2018a, 2018b). In the case of the electronically identified

$2743 \mathrm{D}$ bull, the record was implemented with 3D virtual images. The 3D-bull model for

275 morphological evaluation through a scoring system has a series of indirect advantages, related to

276 both animal health and welfare. The evaluation of animal morphology raised on farms can be

277 promoted also when sanitary restrictions to the movement of animals are in force. As an external

278 threat considered in the SWOT analysis, the presence of infectious diseases may impact

279 negatively on animal movements outside the farm. For instance, in the case of Blue Tongue

280 positivity in sheep of a given region, cattle movements are also restricted as bovines are a natural

281 reservoir of the virus, despite not being clinically involved. Thus, participation in fairs, as well as

282 movement for trading are forbidden, with consequent profit losses. The SWOT analysis pointed

283 to different opportunities offered by the introduction of the 3D model for the evaluation of bull

284 morphology oriented to an up-to-date competitive strategy for the sector. In fact, the analysis of

285 the process "as is" and "to be" clearly highlights how the digital 3D model performance on the

286 basis of the PPV can implement the evaluation system in a smart, contactless and automated

287 way, which is easily shareable and accessible, whereas the $2 \mathrm{D}$ scoring system does not. The 
288 threat of external factors may be the most difficult aspect to deal with. So-called red meat

289 consumption may decrease in the future, unless appropriate marketing strategies and adequate

290 public information are prompted. This threat was considered in the SWOT analysis due to the

291 increasingly aging population and their choice to prefer so-called "white meat" (that of poultry

292 and rabbit). In addition, climate changes may pose the question of environmentally sustainable

293 farming systems, with a potential contraction of meat consumption. Finally, ethical movements

294 against animal product consumption may also influence market choices.

295 Conclusions

296 The results obtained from testing the feasibility of an innovative and technologically advanced

297 methodological approach based on the implementation of an RIFD and 3D imaging system

298 aimed to provide a general overview of valuable opportunities offered by the upgrade of the

299 current system. The instrumental evaluation of bull morphology of the Charolaise breed in a

300 completely digital 3D-image successfully reflects that of the morphology of the live animal. The

301 upgrade into a high-tech system for the evaluation of the breeding bull shows several potential

302 applications as illustrated in the SWOT analysis leading to the innovation of the process. In

303 perspective, the opportunities offered by such an innovative methodological approach may lead

304 to the scale up of the integrated system based on individual RFID identification along with that

305 of 3D digital image of the bull. In fact, the model has the potential for virtual archive creation

306 and the experimental approach appears highly encouraging for further work to check scalability

307 to a large number of animals. Acknowledgements

308 The authors would like to thank Mr. Michele Filigheddu for his cooperation during fieldwork

309 activities on his farm and for providing basic production data. The authors are also thankful to 
310 Dr. Santino Cherchi for his help during the study. The authors express their gratitude to

311 A.N.A.C.L.I.

\section{Reference}

313 Banhazi TM, Lehr H, Black JL, Crabtree H, Schofield P, Tscharke M, et al. 2012. Precision

314 Livestock Farming: An international review of scientific and commercial aspects. International

315 Journal of Agricultural and Biological Engineering, 5(3):1.

316 Berckmans D. 2014. Precision livestock farming technologies for welfare management in

317 intensive livestock systems. Revue Scientifique Et Technique-Office International Des

318 Epizooties, 33(1):189-96.

319 Briggs HM, Briggs DM. 1980. Modern Breeds of Livestock. Fourth Edition. Macmillan

320 Publishing, University of Wisconsin, Madison, USA.

321 Burrow H M, Corbet N J. 2000. Genetic and environmental factors affecting temperament of

322 zebu and zebu-derived beef cattle grazed at pasture in the tropics. Australian Journal of

323 Agricultural Research, 51:155-162.

324 Burrow HM, Dillon RD.1997. Relationship between temperament and growth in a feedlot and

325 commercial carcass traits in Bos indicus crossbreds. Australian Journal of Experimental

326 Agriculture, 37:407-411.

327 Cappai MG, Picciau M, Nieddu G, Bitti MPL, Pinna W. 2014. Long term performance of RFID

328 technology in the large scale identification of small ruminants through electronic ceramic

329 boluses: Implications for animal welfare and regulation compliance. Small Ruminant Research, $330 \quad 117: 169-175$. 
331 Cappai MG, Rubiu NG, Nieddu G, Bitti MPL, Pinna W. 2018a. Analysis of fieldwork activities

332 during milk production recording in dairy ewes by means of individual ear tag (ET) alone or plus

333 RFID based electronic identification (EID). Computers and Electronics in Agriculture, 144:324-

334328.

335 Cappai MG, Rubiu NG, Pinna W. 2018b. Economic assessment of a smart traceability system

336 (RFID+DNA) for origin and brand protection of the pork product labelled "suinetto di

337 Sardegna”. Computers and Electronics in Agriculture, 145:248-253.

338 D’Eath RB, Jack M, Futro A, Talbot D, Zhu Q, Barclay D, Baxter EM. 2018. Automatic early

339 warning of tail biting in pigs: 3D cameras can detect lowered tail posture before an outbreak.

$340 \quad$ PLoS ONE 13(4): e0194524.

341 De Souza Fonseca PA, Id-Lahoucine S, Reverter A, Medrano JF, Fortes MS, Casellas J, Miglior

342 F, Brito L, Carvalho MRS, Schenkel FS, Nguyen LT, Porto-Neto LR, Thomas MG, Cánovas A.

343 2018.Combining multi-OMICs information to identify key-regulator genes for pleiotropic effect

344 on fertility and production traits in beef cattle. PLOS ONE

345 https://doi.org/10.1371/journal.pone.0205295

346 Fournel S, Rousseau AN, Laberge B. 2017. Rethinking environment control strategy of confined

347 animal housing systems through precision livestock farming. Biosystems Engineering, 155:96348123.

349 Gibb DJ, McAllister TA, Huisma C, Wiedmeier RD. 1998. Bunk attendance of feedlot cattle 350 monitored with radio frequency technology. Canadian Journal of Animal Science, 78:707-710.

351 Guatri L. 1991. La teoria di creazione del valore. Una via Europea. EGEA, Milano Italy. 
352 Kosgro J. 2014. Estimation of pig weight using a Microsoft Kinect prototype imaging system.

353 Computers and Electronics in Agriculture, 109:32-35.

354 Leal WS, Costa RF, Cardoso LL, Mendonça, FS, Cardoso FF, Yokoo MJ, Weaber RL. 2018.

355 Bio-economic Model Predicts Economic Values for Beef Production. Kansas Agricultural

356 Experiment Station Research Reports, 4:1-4. https://doi.org/ 10.4148/2378-5977.7534.

357 Moore KL, Mrode R, Coffey MP. 2017. Genetic parameters of Visual Image Analysis primal cut

358 carcass traits of commercial prime beef slaughter animals. Animal, 11:10, 1653-1659.

359 Nkrumah JD, Crews DH Jr, Basarab JA, Price MA, Okine EK, Wang Z, Li C, Moore SS. 2007.

360 Genetic and phenotypic relationships of feeding behavior and temperament with performance,

361 feed efficiency, ultrasound, and carcass merit of beef cattle. Journal of Animal Science, 85:2382-

3622390.

363 Robinson DL, Oddy V H. 2004. Genetic parameters for feed efficiency, fatness, muscle area and

364 feeding behavior of feedlot finished beef cattle. Livestock Production Science, 90:255-270.

365 Schwartzkopf-Genswein KS, Atwood S, McAllister TA. 2003. Use of remote bunk monitoring to

366 record effect of breed, feeding regime and weather on feeding behavior and growth performance

367 of cattle. Canadian Journal of Animal Science, 83:29-38.

368 Soulat J, Picard B, Léger S, Monteils V. 2018. Prediction of beef carcass and meat quality traits

369 from factors characterising the rearing management system applied during the whole life of

370 heifers. Meat Science, 140:88-100. 
371 Sowell BF, Bowman JGP, Branine ME, Hubbard ME. 1998. Radio frequency technology to

372 measure feeding behavior and health of feedlot steers. Applied Animal Behaviour Science, $373 \quad 59: 277-284$.

374 Su H, Golden B, Hyde L, Sanders S, Garrick D. 2017. Genetic parameters for carcass and 375 ultrasound traits in Hereford and admixed Simmental beef cattle: Accuracy of evaluating carcass 376 traits. Journal of Animal Science, 95(11): 4718-4727.

377 Voisinet BD, Grandin T, Tatum JD, O’Connor SF, Struthers JJ. 1997. Feedlot cattle with calm

378 temperaments have higher average daily gains than cattle with excitable temperaments. Journal 379 of Animal Science, 75:892-896.

380 Wu J, Tillett R, Mcfarlane N J B, Ju X, Siebert JP, Schofield P. 2004. Extracting the three-

381 dimensional shape of live pigs using stereo photogrammetry. Computers and Electronics in 382 Agriculture, 44(3):203-222. 


\section{Table $\mathbf{1}$ (on next page)}

Scheme of the SWOT analysis carried out on the basis of intrinsic and extrinsic factors of the innovation of process for Charolaise bull morphology valorization 


\begin{tabular}{|c|c|c|c|}
\hline \multirow{2}{*}{\multicolumn{2}{|c|}{ SWOT analysis }} & \multicolumn{2}{|c|}{ Intrinsic factors } \\
\hline & & Strenghts & Weakness \\
\hline $\begin{array}{l}\mathbf{E} \\
\mathbf{x} \\
\mathbf{t} \\
\mathbf{r} \\
\mathbf{i} \\
\mathbf{n} \\
\mathbf{S} \\
\mathbf{i}\end{array}$ & Opportunities & $\begin{array}{l}\text { DEVELOPMENT OF } \\
\text { STRATEGIES TO } \\
\text { INCREASE } \\
\text { OPPORTUNITIES }\end{array}$ & $\begin{array}{l}\text { MINIMIZATION OF } \\
\text { THREATS TO } \\
\text { IMPROVE } \\
\text { OPPORTUNITIES }\end{array}$ \\
\hline $\begin{array}{l}\mathbf{F} \\
\mathbf{a} \\
\mathbf{c} \\
\mathbf{t} \\
\mathbf{0} \\
\mathbf{r} \\
\mathrm{s}\end{array}$ & Threats & $\begin{array}{l}\text { EXPLOIT STRENGTHS } \\
\text { TO REDUCE } \\
\text { THREATS }\end{array}$ & $\begin{array}{l}\text { PLANNING OF } \\
\text { STRATEGIES OF } \\
\text { DEFENSE TO REDUCE } \\
\text { THREATS }\end{array}$ \\
\hline
\end{tabular}




\section{Table 2 (on next page)}

Body measures of the live animal and respective 3D model. In vivo and virtual values are reported as means and pooled-SD, express in meter. Statistic significance is set for p-value $<0.05$ 


\begin{tabular}{lllll}
\hline Body measures (m) & in vivo & virtual & pooled-SD & p-value \\
\hline Topline & 1.55 & 1.53 & 0.02 & 0.296 \\
Wither height & 1.46 & 1.44 & 0.01 & 0.069 \\
Rear trimness & 0.50 & 0.50 & 0.01 & 0.561 \\
& & & & \\
Performance of the 3D bull & & & & \\
TPR \% & 80 & & \\
TNR \% & 70 & & \\
PPV \% & 89 & & \\
Accuracy \% & & 100 & & \\
\hline
\end{tabular}




\section{Table 3(on next page)}

Scheme of the SWOT analysis emerged from the analysis of the process for Charolaise bull morphology valorization 
1 Table 3 Scheme of the SWOT analysis emerged from the analysis of the process for Charolais

2 bull morphology valorization.

\begin{tabular}{|c|c|c|}
\hline SWOT analysis & \multicolumn{2}{|c|}{ Valorization of Charolais breeding bull morhology } \\
\hline Intrinsic factors & $\begin{array}{l}\text { Strengths } \\
\text { - Competitiveness of bull genetic value } \\
\text { - Experienced farmers } \\
\text { - Worldwide market } \\
\text { - AI diffused for semen trade } \\
\text { - High dressing \% of progeny }\end{array}$ & $\begin{array}{l}\text { Weaknesses } \\
\text { - Restrictions of animal movement } \\
\text { - Costs of transport } \\
\text { - Stressful conditions } \\
\text { - Technology delay }\end{array}$ \\
\hline Extrinsic factors & $\begin{array}{l}\text { Opportunities } \\
\text { - Visibility of bull morphology } \\
\text { - Generational change } \\
\text { - Automation of operations } \\
\text { - Limited investment to update the system } \\
\text { - Virtual net of buyers/suppliers } \\
\text { - E-commerce potentials }\end{array}$ & $\begin{array}{l}\text { Threats } \\
\text { - Aging population } \\
\text { - Ethical trends on animal } \\
\text { product consumption } \\
\text { - Old fashioned scoring system } \\
\text { - Climate change } \\
\text { - Standardization of the system } \\
\text { - Infectious disease }\end{array}$ \\
\hline
\end{tabular}




\section{Figure 1}

Actual 2D grid used for morphology scoring in beef cattle

The scheme displays both somatometric measures and confomation scoring of beef cattle. Adapted from ANACLI 2009. 

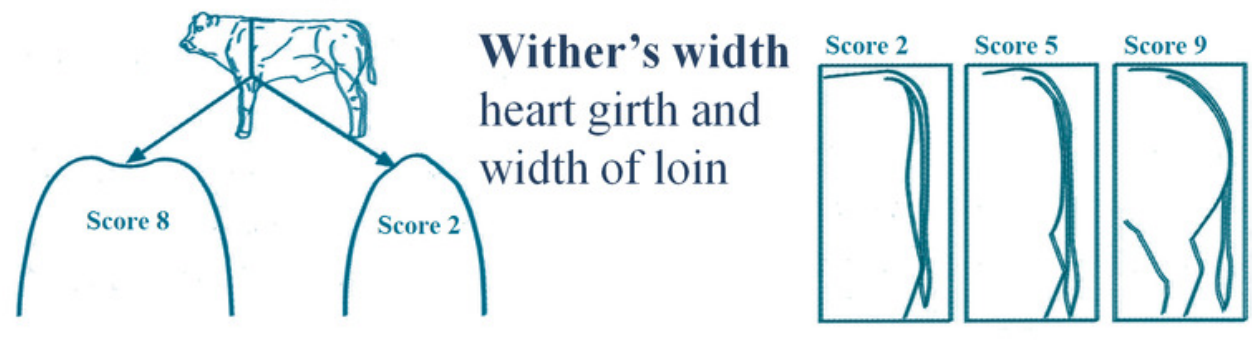

\section{Rear quarter}

round and trimness
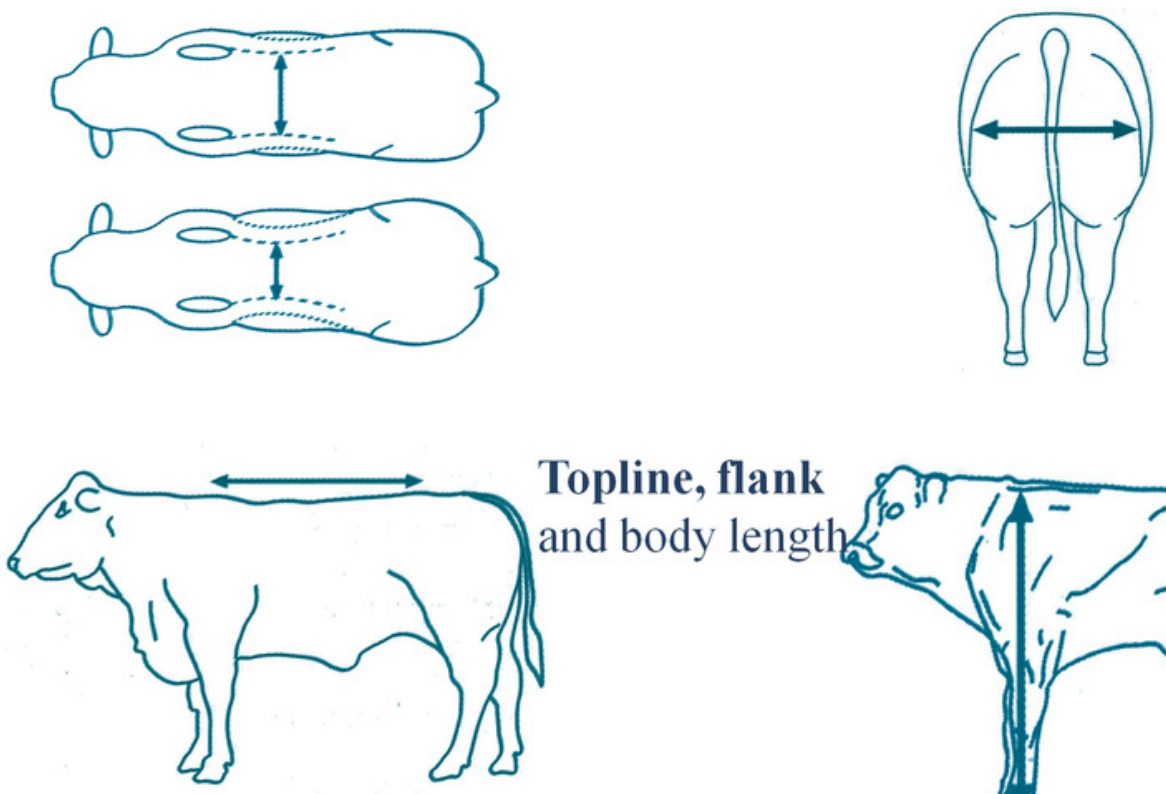

Topline, flank and body length
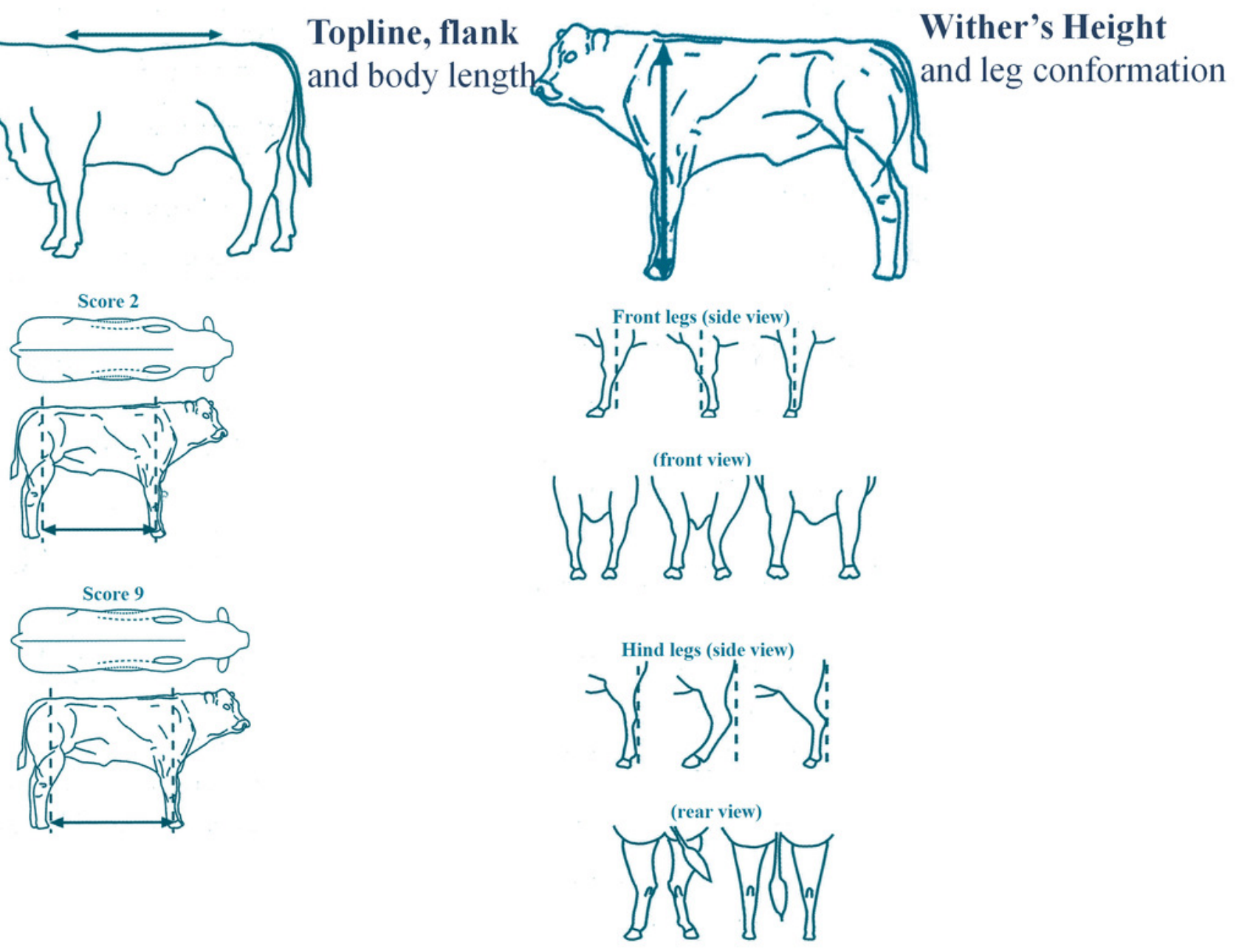


\section{Figure 2}

Geo-referenced $360^{\circ}$ - image capture system in farm

The operator captured multiple consequent images with an overlap of at least $70 \%$, moving around the bull that stood in the center of the circle. 


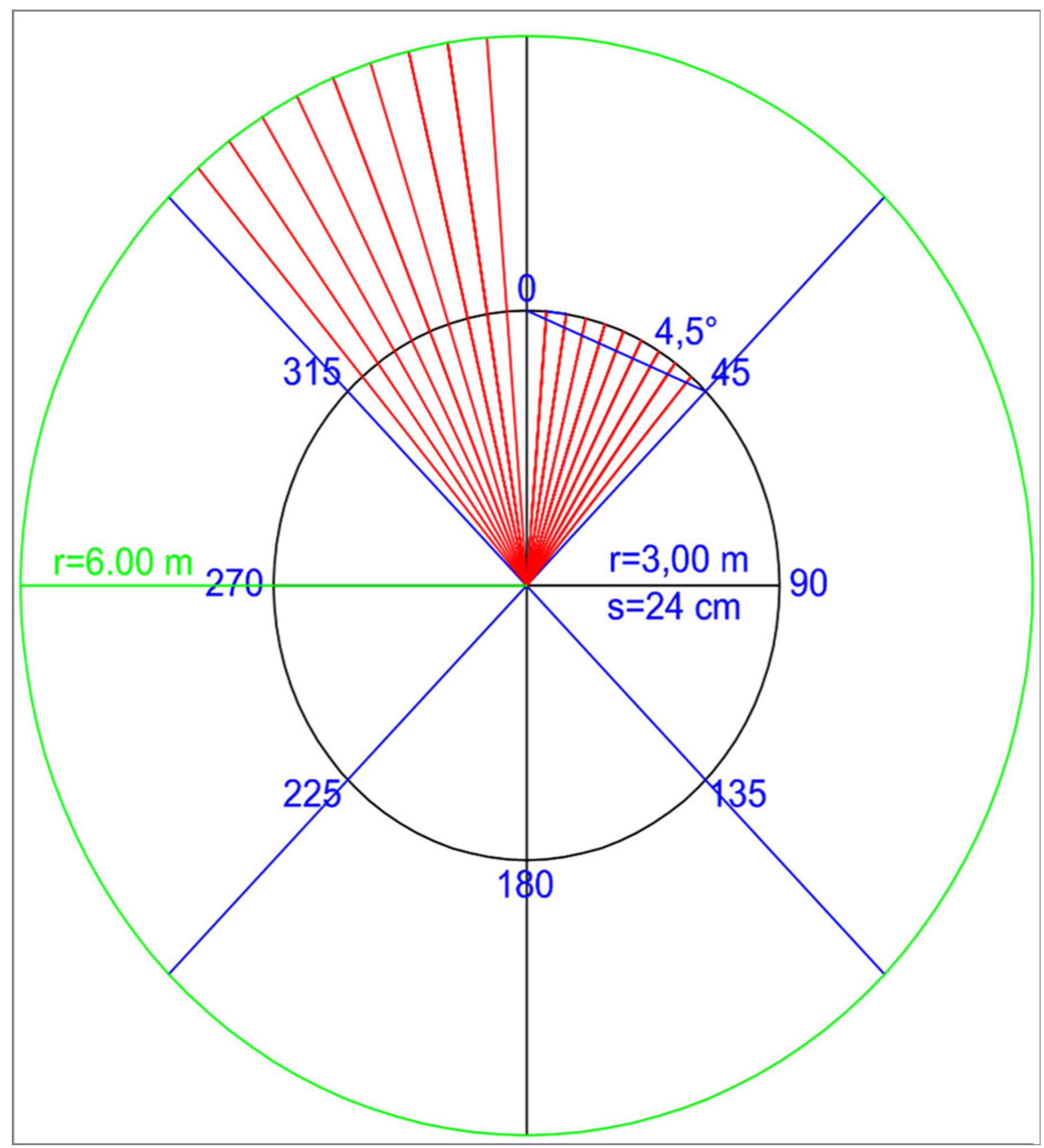


Figure 3

Series of masks generated from the chunks to eliminate background unnecessary objects
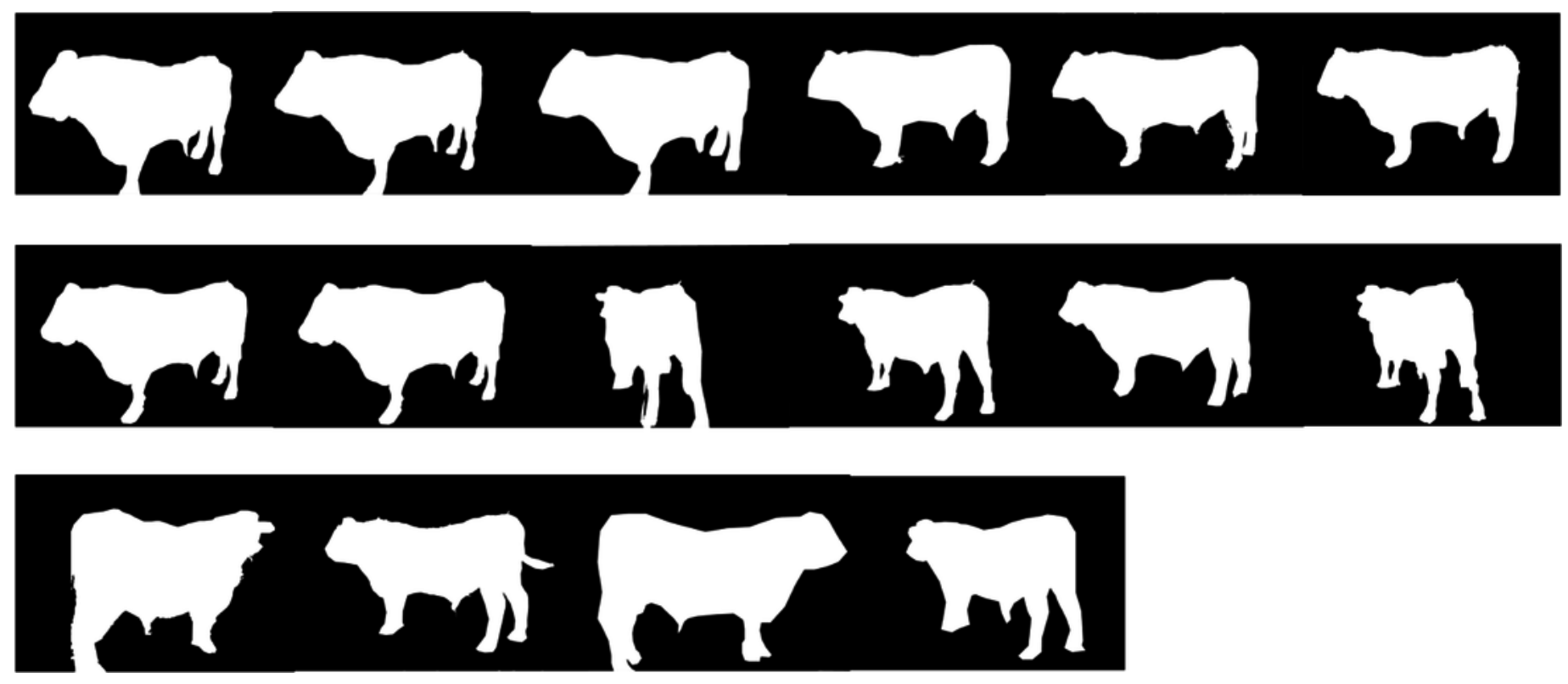
Figure 4

Results from the dense point cloud of the Charolaise bull

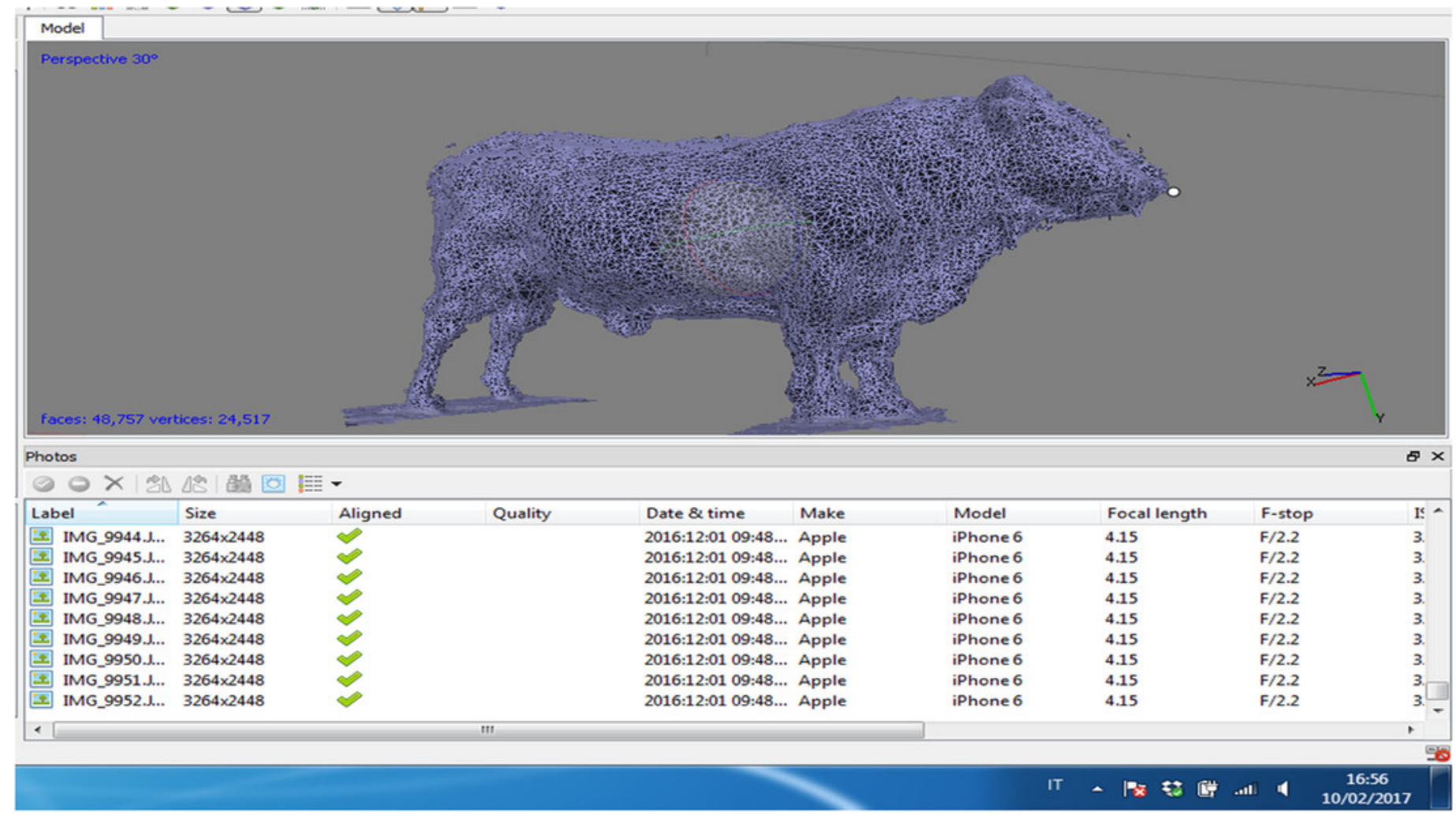




\section{Figure 5}

Body measure taken on the 3D-bull model. Sequence of the topline (upper row), wither's height (middle row) and rear trimness (bottom row)

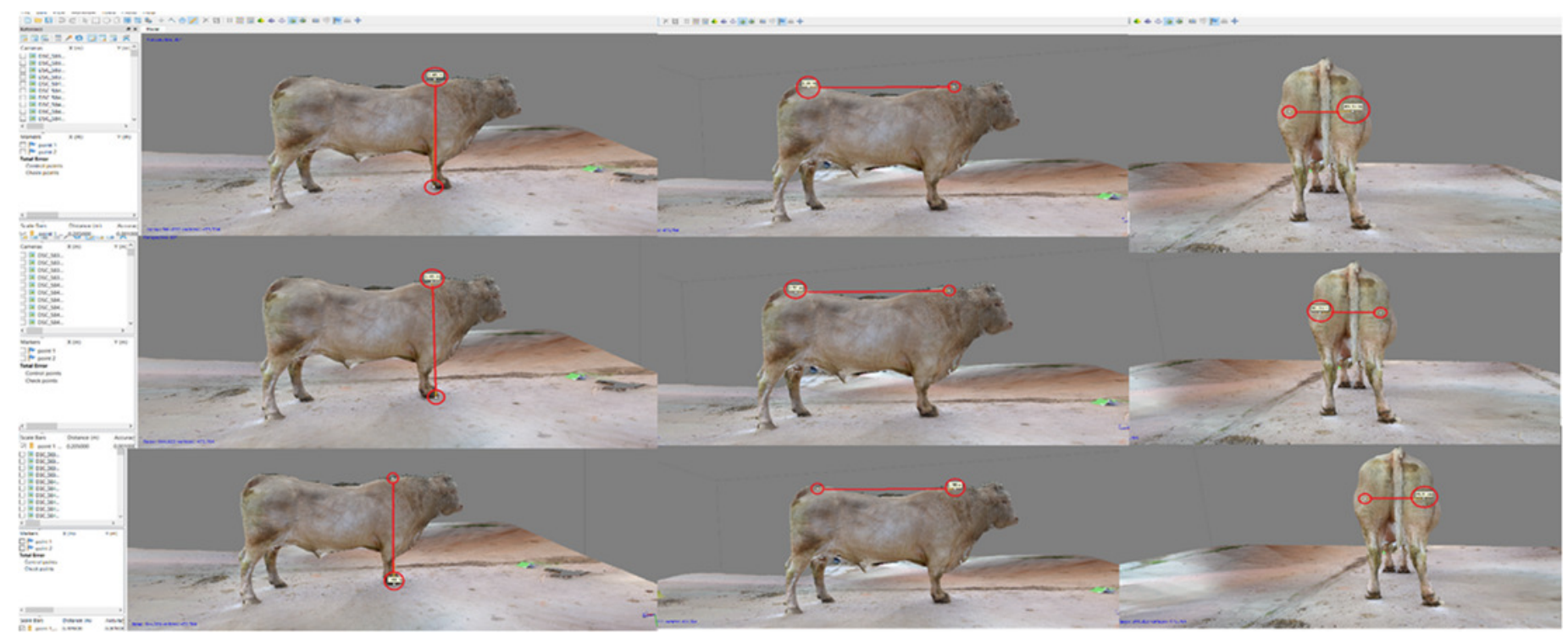

